\title{
ESTUDO DA VISCOSIDADE DE SOLUÇÕES PROTEICAS ATRAVÉS DO ANALISADOR RÁPIDO DE VISCOSIDADE (RVA)
}

\section{Study of the viscosity of protein solutions through the rapid viscosity analyzer (RVA)}

\author{
Maura P. Alves ${ }^{1}$, Ítalo T. Perrone ${ }^{l^{*}}$, Alisson Borges de Souza ${ }^{2}$, Rodrigo Stephani ${ }^{2}$, \\ Cláudia Lúcia de Oliveira Pinto ${ }^{3}$, Antônio F. de Carvalhol
}

\begin{abstract}
RESUMO
Este trabalho objetivou determinar pelo analisador rápido de viscosidade (RVA) as curvas de viscosidade de soluções preparadas a partir de concentrados proteicos de soro (CPSs) e determinar o tempo ideal de tratamento térmico visando à obtenção da viscosidade máxima nesta etapa. Os CPSs, produzidos a partir de amostras de soro submetidas inicialmente a tratamentos térmicos e de microfiltração, apresentaram composição centesimal compatível com padrões internacionais com diferença significativa $(\mathrm{p}<0,05)$ entre as amostras apenas para o teor de gordura. Pela análise dos perfis viscográficos observou-se que os CPSs produzidos a partir de soro microfiltrado apresentaram valores de viscosidade mais altos que aqueles submetidos ao tratamento térmico para todos os dados coletados. Além disso, o tempo ideal de tratamento térmico das soluções de CPSs visando maximizar a viscosidade durante o aquecimento foi de, aproximadamente, 10 minutos. Os resultados possibilitam a aplicação dos CPSs pelas indústrias alimentícias considerando a característica desejada no produto final, sendo que o RVA mostrou-se uma ferramenta apropriada para estudo de funcionalidade desses concentrados.
\end{abstract}

Palavras-chave: química de leite; tratamento térmico; soro proteínas.

\begin{abstract}
This study aimed to determine viscosity curves prepared from whey protein concentrates (WPCs) by the rapid viscosity analyzer (RVA) and determine the optimal

1 Universidade Federal de Viçosa (UFV), Departamento de Tecnologia de Alimentos, Av. P.H. Rolfs, Campus Universitário, 36570-000, Viçosa, MG, Brasil. E-mail: italo.perrone@ufv.br

2 Gemacom Tech, Juiz de Fora, MG, Brasil.

3 Empresa de Pesquisa Agropecuária de Minas Gerais (EPAMIG), Unidade Regional Epamig Zona da Mata, Viçosa, MG, Brasil.

* Autor para correspondência.
\end{abstract}

Recebido / Received: 08 /07/2013

Aprovado / Approved: 14/02/2014 
heat treatment time in order to obtain the maximum viscosity solutions at this stage. The WPCs produced from whey samples initially subjected to thermal treatment and microfiltration presented composition compatible with the international standards, with a significant difference $(\mathrm{p}<0.05)$ for fat concentration. Viscographic profiles indicated that WPCs produced from microfiltered whey had higher viscosities than those subjected to heat treatment. In addition, 10 min was determined to be the optimal length of time for heat treatment in order to maximise WPCs viscosity. These results indicate that WPC production can be designed for different food applications. Finally, a rapid viscosity analyzer was demonstrated to be an appropriate tool to study the application of whey proteins in food systems.

Keywords: dairy chemistry; heat treatment; whey proteins.

\section{INTRODUÇÃO}

As proteínas do leite compreendem duas frações principais: as caseínas $(80 \%)$ e as proteínas do soro $(20 \%)$. A caseína encontrase organizada no leite sob a forma de micelas esféricas e pode ser definida como a proteína precipitada pela acidificação do leite a um valor de $\mathrm{pH}$ próximo a 4,6, sendo assim insolúvel em seu ponto isoelétrico (Walstra et al., 2006). As proteínas do soro são solúveis em ampla faixa de $\mathrm{pH}$, apresentam estrutura globular e contêm pontes dissulfeto que conferem a elas um determinado grau de estabilidade estrutural (Aimutis, 2004). As duas principais frações proteicas do soro são a $\beta$-lactoglobulina ( $\beta$ Lg) e a $\alpha$-lactoalbumina ( $\alpha$-La) que estão presentes em maior concentração e constituem, aproximadamente, $70 \%$ das proteínas totais do soro (Metsämuuronen; Nyström, 2009).

A concentração do soro leva à formação de produtos proteicos que podem ser utilizados como ingredientes, com melhoria nas propriedades tecno-funcionais dos alimentos (solubilidade, gelificação, viscosidade, emulsificação, formação de espuma). Além disso, esses produtos proteicos apresentam grande potencial de utilização em alimentos por também possuírem componentes aos quais se atribuem propriedades biológicas importantes (Walzem et al., 2002) como atividade antimicrobiana (Pellegrini et al., 2001), anticâncer (McIntosh; Le Leu, 2001;
Belobrajdic et al., 2003; Kent et al., 2003), proteção contra stress oxidativo (Nicodemo et al., 2000; Bounous; Molson, 2003), problemas cardiovasculares (Davis et al., 2003; Vermeirssen et al., 2003), entre outras.

As propriedades tecno-funcionais das proteínas alimentares são afetadas por diversos fatores que incluem propriedades intrínsecas, tais como a sequência de aminoácidos, estrutura e flexibilidade molecular da proteína e o caráter hidrofílico ou hidrofóbico de sua superfície. Também fatores extrínsecos influenciam nessas propriedades tecno-funcionais das proteínas como $\mathrm{pH}$, temperatura, força iônica e as interações com outros ingredientes alimentares (Patino et al., 2003; Niño et al., 2005).

A avaliação do comportamento da viscosidade de soluções proteicas, utilizadas como ingredientes nas indústrias alimentícias, é essencial já que essa propriedade está associada aos atributos do produto final processado. O RapidVisco ${ }^{\mathrm{TM}}$ Analyser $\left(\mathrm{RVA}^{\mathrm{TM}}\right)$ - Analisador Rápido de Viscosidade - é um viscosímetro rotacional capaz de mensurar continuamente a viscosidade de uma amostra sob condições controladas de temperatura (Booth; Bason, 2007). Devido a suas características, Bennett et al. (2007) sugeriram o uso do RVA na caracterização de propriedades tecno-funcionais dos ingredientes e alimentos ricos em proteínas.

Stephani et al. (2012) avaliaram o comportamento da evolução da viscosidade de 
soluções preparadas a partir de produtos lácteos proteicos (MPPS), em diferentes concentrações, quando submetidas a diferentes condições de processamento térmico simuladas pelo RVA.

Dessa forma, esse trabalho objetivou determinar por RVA as curvas de viscosidade de soluções preparadas a partir de CPSs e determinar o tempo ideal de tratamento térmico visando à obtenção da viscosidade máxima nesta etapa.

\section{MATERIAL E MÉTODOS}

\section{Procedimento experimental}

As atividades deste trabalho foram conduzidas no Laboratório de Pesquisa em
Ciência e Tecnologia de Leite e Derivados e no Laticínio Escola, do Departamento de Tecnologia de Alimentos da Universidade Federal de Viçosa e no Laboratório de Pesquisa, Desenvolvimento e Inovação da empresa Gemacom Tech, em Juiz de Fora. $\mathrm{O}$ soro de leite utilizado neste trabalho foi fornecido por uma indústria localizada na Zona da Mata Mineira, sendo obtido a partir da fabricação de queijo Minas Frescal. O soro foi armazenado sob refrigeração a $4^{\circ} \mathrm{C}$ até $\mathrm{o}$ momento do seu uso e foi centrifugado antes do início de cada tratamento. O delineamento foi inteiramente casualizado, com quatro tratamentos aplicados a soro de leite e cinco repetições, sendo o experimento realizado em três etapas principais. Na primeira etapa (S1), as amostras de soro foram microfiltradas

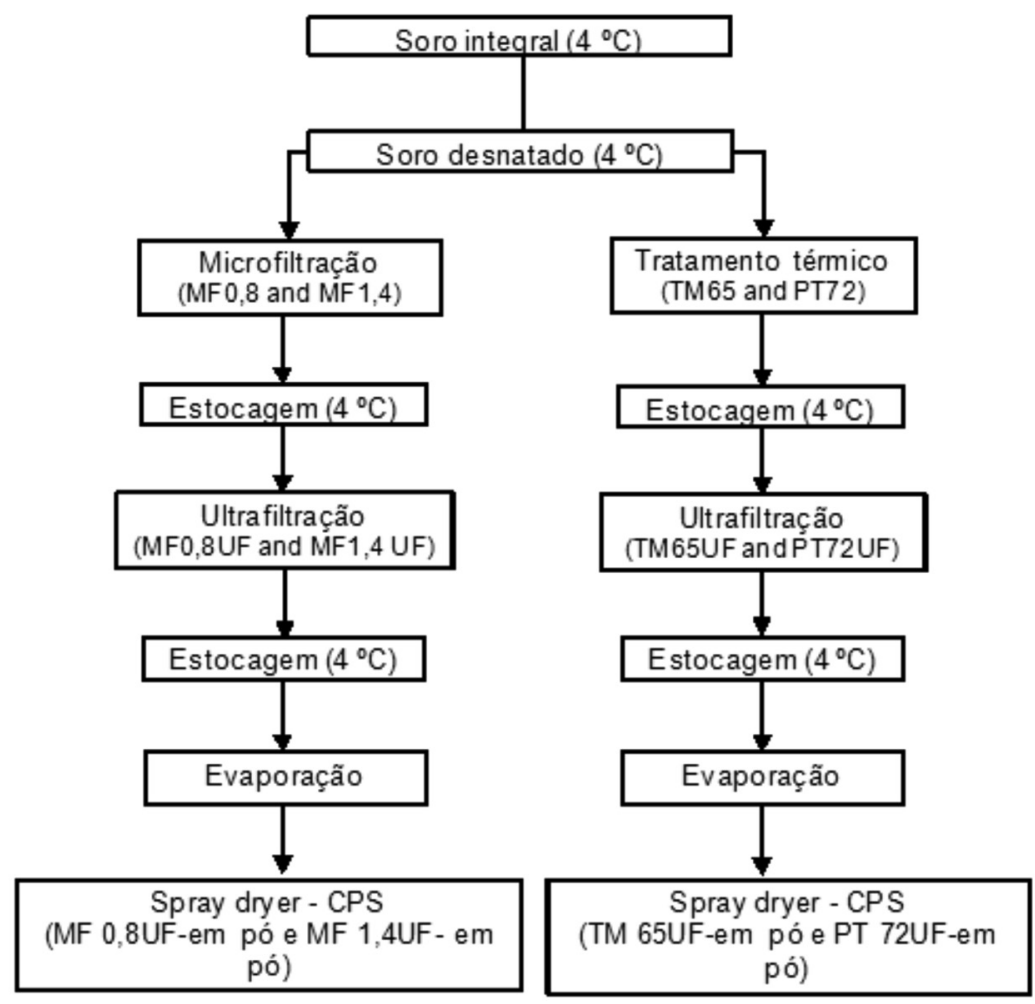

Figura 1 - Etapas do procedimento experimental 
utilizando membrana de $0,8 \mu \mathrm{m}$ (Tratamento 01 - MF0,8) ou 1,4 $\mu \mathrm{m}$ de diâmetro do poro (Tratamento $02-\mathrm{MF} 1,4)$, termizadas a $65^{\circ} \mathrm{C}$ por 15 segundos (Tratamento 03 -TM65) ou ainda pasteurizadas a $72^{\circ} \mathrm{C}$ por 15 segundos (Tratamento 04 - PT72). Na segunda etapa (S2) cada tratamento foi submetido à operação de ultrafiltração (MF 0,8UF, MF 1,4UF, TM 65UF e PT 72UF). Finalmente, na terceira etapa (S3) as amostras foram submetidas às operações de evaporação a vácuo, em evaporador rotativo de bancada, e secagem em equipamento spray dryer, produzindo-se os CPSs. Esses tratamentos foram avaliados quanto a: gordura, extrato seco total, umidade, cinzas, e proteínas totais, e atividade de água (Aw). Soluções preparadas a partir dos CPSs produzidos foram também avaliadas quanto à viscosidade. Um esquema geral de todo procedimento realizado pode ser visualizado na Figura 1.

\section{Caracterização dos equipamentos}

Para a microfiltração, o soro foi aquecido a $50^{\circ} \mathrm{C}$ e filtrado tangencialmente através de uma membrana cerâmica tubular "Membralox ${ }^{\circledR}$ " (Tetra Pak ${ }^{\circ}$ Processing, França) com poros de tamanho 0,8 e $1,4 \mu \mathrm{m}$. Os tratamentos de termização $\left(65^{\circ} \mathrm{C}\right.$ por 15 segundos) e pasteurização $\left(72^{\circ} \mathrm{C}\right.$ por 15 segundos) foram realizados em trocador de calor a placas (Biasinox, Brasil). A ultrafiltração do soro foi realizada em uma membrana de polissulfona do tipo espiral "Koch Membranes" (WGM sistemas, Brasil) com uma massa molar de corte de $10 \mathrm{kDa}$, em sistema aberto. A operação de evaporação a vácuo ocorreu à temperatura de $60 \pm 2{ }^{\circ} \mathrm{C}$ em evaporador rotativo micro processado de bancada (Quimis modelo Q344M2, Brasil). A evaporação foi conduzida de modo a concentrar o soro até um teor de sólidos de $25 \%$ antes da etapa de secagem. A operação de secagem ocorreu em spray dryer piloto de único estágio modelo MSD 1.0, com atomizador de bico de pressão (Labmaq,
Brasil), com uma vazão de 35 litros de ar de atomização por hora, 1,10 litros de produto por hora e $3,10 \mathrm{~m}^{3}$ de ar por minuto no sistema de aquecimento.

\section{Análises físico-químicas}

A determinação do potencial hidrogeniônico foi realizada utilizando-se medidor de pH (Dimed DM 20, São Paulo, Brasil), o teor de gordura foi determinado através do método de Gerber e o resíduo mineral fixo por meio da incineração das amostras a $550^{\circ} \mathrm{C}$, sendo estas descritas por Wehr; Frank (2004). A atividade de água a $25^{\circ} \mathrm{C}$ foi determinada utilizando-se medidor digital Aqualab (Decagon 3TE, Decagon Devices Inc., USA). A determinação do extrato seco foi realizada pelo método gravimétrico (IDF 21B: 1987) e o teor de nitrogênio total (NT) foi obtido pelo método de Kjeldahl (IDF 20B:1993).

\section{Análises de viscosidade utilizando o deter- minador rápido de viscosidade (RVA)}

O equipamento RVA utilizado neste trabalho foi o modelo Series 4 (RVA-4) da Newport Scientific instalado na empresa Gemacom Tech na unidade industrial de Juiz de Fora, Minas Gerais, e gentilmente cedido para os estudos.

Nas simulações de processamento térmico, as soluções de CPSs foram preparadas em duplicatas diretamente na cuba de aquecimento do RVA e os cálculos foram realizados para que essas soluções apresentasse m $25 \mathrm{~g}$ de massa final, nas concentrações de 0,4 g.g $\mathrm{g}^{-1}$ e $0,5 \mathrm{~g} \cdot \mathrm{g}^{-1}$ (base seca em água) para cada tratamento. Para garantir a completa uniformização das soluções, a rotação do RVA foi configurada para 104,7 rad. $\mathrm{s}^{-1}$ durante os primeiros 60 segundos, a uma temperatura constante de $30^{\circ} \mathrm{C}$. O software utilizado para coleta dos dados foi o Thermocline for Windows (TCW, Austrália). A configuração da simulação de processamento 
térmico está descrita na Tabela 1 . As condições de tempo e temperatura foram padronizadas para que as soluções de CPSs pudessem exibir valores mais altos de viscosidade (Stephani, 2010), e foram de $85^{\circ} \mathrm{C}$ por 15 minutos para cada amostra.

Os perfis viscográficos foram interpretados em relação a quatro diferentes dados: viscosidade de pico $-\mathrm{V}_{\mathrm{p}}$, viscosidade de retenção $-V_{R}$, viscosidade final $-V_{F}$ e área por unidade tempo - $/ /$ t. Os cálculos de integração dos perfis viscográficos foram realizados no software Microcaltm Origin ${ }^{\circledR}$ versão 6.0 (Microcal Software, Reino Unido). Todos os cálculos de integração foram feitos com os perfis viscográficos a partir do tempo 63 segundos, descartando assim o tempo de agitação com velocidade de 104,7 $\mathrm{rad} . \mathrm{s}^{-1}$.

\section{Análise estatística}

Os resultados de composição centesimal

Tabela 1 - Configuração do processamento térmico empregado no RVA

\begin{tabular}{ccc}
\hline Tempo & Comando & Valor \\
\hline $0 \min 00 \mathrm{~s}$ & Temperatura $\left({ }^{\circ} \mathrm{C}\right)$ & 30 \\
$0 \mathrm{~min} 00 \mathrm{~s}$ & Rotação $\left(\right.$ rad. $\left.\mathrm{s}^{-1}\right)$ & 104,7 \\
$1 \mathrm{~min} 00 \mathrm{~s}$ & Rotação $\left(\right.$ rad. $\left.\mathrm{s}^{-1}\right)$ & 15,7 \\
$1 \mathrm{~min} 00 \mathrm{~s}$ & Temperatura $\left({ }^{\circ} \mathrm{C}\right)$ & 30 \\
$11 \mathrm{~min} 00 \mathrm{~s}$ & Temperatura $\left({ }^{\circ} \mathrm{C}\right)$ & 85 \\
$26 \mathrm{~min} 00 \mathrm{~s}$ & Temperatura $\left({ }^{\circ} \mathrm{C}\right)$ & 85 \\
$36 \min 00 \mathrm{~s}$ & Temperatura $\left({ }^{\circ} \mathrm{C}\right)$ & 30 \\
$41 \min 00 \mathrm{~s}$ & Temperatura $\left({ }^{\circ} \mathrm{C}\right)$ & 30 \\
$41 \mathrm{~min} 01 \mathrm{~s}$ & Término & $\mathrm{X}$ \\
\hline
\end{tabular}

Tabela 2 - Valores médios dos resultados das análises de composição centesimal e físico-química realizadas nas amostras de CPSs

Amostras

\begin{tabular}{|c|c|c|c|c|}
\hline Análises & $\begin{array}{c}\text { PT 72UF - } \\
\text { Pó }\end{array}$ & $\begin{array}{c}\text { TM 65UF - } \\
\text { Pó }\end{array}$ & $\begin{array}{c}\text { MF } 0,8 \mathrm{UF} \text { - } \\
\text { Pó }\end{array}$ & $\begin{array}{c}\text { MF } 1,4 U F \text { - } \\
\text { Pó }\end{array}$ \\
\hline Gordura $\left(\% \mathrm{~m} \cdot \mathrm{v}^{-1}\right)$ & $2,30^{\mathrm{a}}$ & $2,30^{\mathrm{a}}$ & $0,00^{\mathrm{b}}$ & $0,00^{\mathrm{b}}$ \\
\hline Proteína $\left(\% \mathrm{~m} \cdot \mathrm{m}^{-1}\right)$ & $32,30^{\mathrm{a}}$ & $34,90^{\mathrm{a}}$ & $33,60^{\mathrm{a}}$ & $34,80^{\mathrm{a}}$ \\
\hline Cinzas $\left(\% \mathrm{~m} \cdot \mathrm{m}^{-1}\right)$ & $6,30^{\mathrm{a}}$ & $6,40^{\mathrm{a}}$ & $6,80^{\mathrm{a}}$ & $6,70^{\mathrm{a}}$ \\
\hline Lactose $^{*}(\%)$ & $54,70^{\mathrm{a}}$ & $52,10^{\mathrm{a}}$ & $55,60^{\mathrm{a}}$ & $54,40^{\mathrm{a}}$ \\
\hline $\operatorname{EST}\left(\% \mathrm{~m} \cdot \mathrm{m}^{-1}\right)$ & $95,60^{\mathrm{a}}$ & $95,70^{\mathrm{a}}$ & $96,00^{\mathrm{a}}$ & $95,90^{\mathrm{a}}$ \\
\hline Umidade $\left(\% \mathrm{~m} \cdot \mathrm{m}^{-1}\right)$ & $4,40^{\mathrm{a}}$ & $4,30^{\mathrm{a}}$ & $4,00^{\mathrm{a}}$ & $4,10^{\mathrm{a}}$ \\
\hline Aw & $0,232^{\mathrm{a}}$ & $0,277^{\mathrm{a}}$ & $0,251^{\mathrm{a}}$ & $0,248^{\mathrm{a}}$ \\
\hline
\end{tabular}

Dados de cinco repetições, análises realizadas em duplicata.

Médias seguidas de pelo menos uma mesma letra, na linha, para cada variável, não diferem entre si ao nível de $5 \%$ de probabilidade pelo teste de Tukey.

* Calculado por diferença

PT 72UF-Pó:CPS produzido a partir do soro pasteurizado a $72^{\circ} \mathrm{C}$ por 15 segundos; TM 65UF-Pó: CPS produzido a partir do soro termizado a $65^{\circ} \mathrm{C}$ por 15 segundos; MF 0,8UF-Pó: CPS produzido a partir do soro microfiltrado utilizando membrana de $0,8 \mu \mathrm{m}$ de diâmetro do poro; MF 1,4UF-Pó: CPS produzido a partir do soro microfiltrado utilizando membrana de 1,4 m de diâmetro do poro. 
e físico-química foram analisados por meio de análise de variância (ANOVA) e pela comparação de médias pelo teste de Tuckey $(\mathrm{p}<0,05)$. Os dados de viscosidade das amostras de CPSs foram estudados por meio de análise descritiva, pelo ajuste a modelos polinomiais de terceira ordem e pela determinação do ponto de máximo de viscosidade das curvas, empregando-se a derivada a segunda do modelo empírico ajustado. Além disso, os dados de viscosidade foram também analisados por meio do coeficiente de correlação de Pearson $(p<0,05)$ para concluir sobre os fatores a serem utilizados na interpretação do perfil viscográfico dos CPSs. Os dados foram analisados por meio do programa estatístico Statistical Analysis System (SAS Institute Inc., 2006) versão 9.2, licenciado para a Universidade Federal de Viçosa.

\section{RESULTADOS E DISCUSSÃO}

Os resultados referentes às análises de composição centesimal e físico-química realizadas nas amostras de CPSs são apresentados na Tabela 2. O teor de gordura entre as amostras que foram inicialmente tratadas pelo calor foi significativamente diferente $(p<0.05)$ em relação às microfiltradas. Este resultado ocorreu pela retenção dos glóbulos de gordura pela membrana de microfiltração, uma vez que a gordura do leite consiste de triacilgliceróis presentes principalmente na forma de glóbulos de gordura com diâmetros entre $0,1 \mu \mathrm{m}$ e $15 \mu \mathrm{m}$ (Brans et al., 2004; García et al, 2012). Quanto aos valores de atividade de água e aos teores de proteína total, cinzas, extrato seco total, umidade e lactose avaliados não foram observadas diferenças significativas $(p>0.05)$ entre os diferentes CPSs, o que indicou controle adequado durante as etapas de processamento.

Os CPSs obtidos pela secagem no spray dryer apresentaram valores de atividade de água próximo a 0,200 , valor indicado por Schuck et al. (2008) como ideal para os lácteos desidratados por minimizar as reações químicas e bioquímicas, e permitir uma melhor conservação do produto. Algumas mudanças na etapa de secagem poderiam reduzir ainda mais a atividade de água das amostras que apresentaram valor mais elevado deste atributo, como por exemplo, o controle da umidade do ar de secagem. Schuck et al. (2008) padronizaram o teor de umidade e a atividade de água de produtos lácteos desidratados por meio do controle da umidade do ar de saída da câmara durante a secagem. Entretanto, como não foi possível controlar este parâmetro no equipamento utilizado, as possíveis soluções seriam a diminuição da taxa de bombeamento de produto, o aumento da temperatura do ar de secagem e o aumento da vazão do ar de entrada.

Não existe uma legislação específica no Brasil para a inspeção das características físico-químicas de concentrados ou isolados proteicos de soro. O Instituto Americano de Produtos Lácteos (ADPI, 2010) estabelece padrões para seleção de produtos lácteos a serem utilizados como ingredientes funcionais e nutritivos em indústrias alimentícias. De acordo com esses valores, o teor de proteína dos produtos resultantes deste estudo mostrou-se um pouco abaixo do teor mínimo de $35 \%$ necessário para CPSs, enquanto o teor de umidade esteve bem próximo ao valor máximo estabelecido de 4\%. Esse último é de grande importância na conservação do produto e determinante no rendimento industrial. Quanto aos demais parâmetros, todos se encontram dentro da faixa de valores estabelecidas pelo Instituto Americano de Produtos Lácteos.

Os perfis viscográficos do processamento térmico $\left(85^{\circ} \mathrm{C}\right.$ por 15 minutos $)$ simulado em RVA para os CPSs, nas duas concentrações avaliadas, são mostrados na Figura 2 e as médias das $\mathrm{V}_{\mathrm{P}}$ (maior viscosidade obtida 
durante o processamento térmico antes do início do resfriamento), $\mathrm{V}_{\mathrm{R}}$ (viscosidade obtida no final do tempo de retenção do processamento térmico), $\mathrm{V}_{\mathrm{F}}$ (última leitura de viscosidade obtida no final da análise) e das $\int / t$ (valor da integração do perfil viscográfico, dividido pelo tempo total da análise), coletadas a partir dos dados obtidos em cada perfil viscográfico são apresentadas na Tabela 3.

A influência da concentração das soluções sobre os valores de $V_{P}, V_{R}$ e $V_{F}$ foi evidente, obtendo-se valores mais elevados de viscosidade com o aumento da concentração para todos os concentrados proteicos avaliados (Figura 2). As amostras de CPSs produzidas a partir de soro microfiltrado (MF0,8UF-Pó e MF 1,4UF-Pó), apresentaram em geral valores de viscosidade mais altos (Tabela 3 ), o que indica a predominância das proteínas do soro no estado globular. Consequentemente permitiu uma maior retenção de água em sua estrutura e portanto, maior viscosidade. Isto indica que o emprego de CPSs para o aumento de viscosidade de soluções, durante o processamento de determinado produto, é otimizado quando a matéria-prima utilizada para obtenção destes pós é submetida a menores intensidades de tratamento térmico.
A viscosidade máxima obtida durante o processamento térmico foi alcançada antes do término do tratamento a $85^{\circ} \mathrm{C}$ por 15 minutos e, portanto, o ponto ótimo de viscosidade foi ultrapassado.

A variação da viscosidade com o tempo durante o tratamento térmico de todas as amostras no RVA foi ajustada a modelos polinomiais de terceira ordem (Tabela 4). A determinação do ponto de inflexão destas equações possibilita a identificação do momento no qual a taxa de aumento infinitesimal da viscosidade com o tempo muda durante a etapa de tratamento das amostras a $85^{\circ} \mathrm{C}$. Pela análise gráfica, este momento corresponde à diminuição da taxa de aumento de viscosidade para as soluções de CPSs, ou seja, a viscosidade das soluções a partir deste ponto começa a aumentar de forma mais lenta. Se o tratamento térmico aplicado às soluções de CPSs fosse de tempo igual ao ponto de inflexão da curva, então a proteína se encontraria na taxa máxima de aumento de viscosidade com o tempo. Os pontos de inflexão para cada tratamento foram calculados ao igualar a derivada à segunda do polinômio de terceira ordem a 0 . O tempo ideal de tratamento térmico para as soluções de CPSs, nas condições do experimento, foi de aproximadamente 10 minutos (valor médio

Tabela 3 - Médias das $V_{P}, V_{R}, V_{F}$ e $\int / t$ dos CPSs para as duas concentrações de estudo

\begin{tabular}{|c|c|c|c|c|c|c|c|c|}
\hline \multirow[b]{2}{*}{ Amostra } & \multicolumn{2}{|c|}{$\begin{array}{l}\text { Viscosidade de } \\
\text { pico (mPa's) }\end{array}$} & \multicolumn{2}{|c|}{$\begin{array}{l}\text { Viscosidade de } \\
\text { retenção (mPa`s) }\end{array}$} & \multicolumn{2}{|c|}{$\begin{array}{l}\text { Viscosidade } \\
\text { final(mPa's) }\end{array}$} & \multicolumn{2}{|c|}{$\begin{array}{l}\text { Área por unidade } \\
\text { de tempo }\left(\mathrm{mPa}^{\circ} \mathrm{s}\right)\end{array}$} \\
\hline & $\begin{array}{c}0,4 \\
\left(\mathrm{~g}^{\cdot} \mathrm{g}^{-1}\right)\end{array}$ & $\begin{array}{c}0,5 \\
\left(g^{\cdot} g^{-1}\right)\end{array}$ & $\begin{array}{c}0,4 \\
\left(g^{\cdot} g^{-1}\right)\end{array}$ & $\begin{array}{c}0,5 \\
\left(g^{\cdot} g^{-1}\right)\end{array}$ & $\begin{array}{c}0,4 \\
\left(g^{\cdot} g^{-1}\right)\end{array}$ & $\begin{array}{c}0,5 \\
\left(g^{\cdot} g^{-1}\right)\end{array}$ & $\begin{array}{c}0,4 \\
\left(g^{\cdot} g^{-1}\right)\end{array}$ & $\begin{array}{c}0,5 \\
\left(g^{\cdot} g^{-1}\right)\end{array}$ \\
\hline PT 72 & 2,0 & 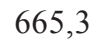 & 68 & 6650 & 49 & 22140 & 43 & 726,2 \\
\hline TM 65UF-Pó & 395,3 & 636 & 393, & 636 & 1244,3 & 2126,0 & 413 & 678,8 \\
\hline MF 0,8UF-Pó & 480,0 & 710,0 & $479, ?$ & & 1727,3 & 2545, & 540,2 & 801,8 \\
\hline MF 1,4UF-Pó & 518,0 & 811,7 & 513,3 & 811,3 & 1972,7 & 2514,7 & 611,9 & 843,8 \\
\hline
\end{tabular}

PT72UF-Pó:CPS produzido a partir do soro pasteurizado a $72^{\circ} \mathrm{C}$ por 15 segundos; TM65UF-Pó: CPS produzido a partir do soro termizado a $65^{\circ} \mathrm{C}$ por 15 segundos; MF0,8UF-Pó: CPS produzido a partir do soro microfiltrado utilizando membrana de $0,8 \mu \mathrm{m}$ de diâmetro do poro; MF1,4UF-Pó: CPS produzido a partir do soro microfiltrado utilizando membrana de $1,4 \mu \mathrm{m}$ de diâmetro do poro. 
do tempo calculado pelo ponto de inflexão Tabela 4).

Os percentuais representados pela área de aquecimento e de resfriamento em relação à área total foram de, aproximadamente, $20 \%$ e $80 \%$, respectivamente (Tabela 4). Esses dados mostram a contribuição de cada etapa do processamento no aumento de viscosidade

Tabela 4 - Área total, área de aquecimento e área de resfriamento, modelos polinomiais de terceira ordem ajustados e pontos de inflexão para cada amostra de CPS

\begin{tabular}{|c|c|c|c|}
\hline \multirow{6}{*}{$\begin{array}{l}\text { PT } 72 \\
\text { UF-Pó }\end{array}$} & & $0,4 \%$ & $0,5 \%$ \\
\hline & Área total & 1076840 & 1782160 \\
\hline & $\begin{array}{l}\text { Área aquecimento/ } \\
\text { percentual da área } \\
\text { total }\end{array}$ & $227030 / 21,1 \%$ & $382089 / 21,4 \%$ \\
\hline & $\begin{array}{l}\text { Área resfriamento/ } \\
\text { percentual da área }\end{array}$ & $850598 / 78,9 \%$ & $1382730 / 77,6 \%$ \\
\hline & Equação & $\begin{array}{c}\mathrm{V}=1,17 \cdot 10^{-6} \mathrm{t}^{3}-4,4 \cdot 10^{-3} \mathrm{t}^{2}+5,7 \mathrm{t}- \\
2,2 \cdot 10^{3}\end{array}$ & $\begin{array}{c}\mathrm{V}=1,7 \times 10^{-6} \mathrm{t}^{3}-6,3 \times 10^{-} \\
{ }^{3} \mathrm{t}^{2}+8,3 \mathrm{t}-3,2 \times 10^{3}\end{array}$ \\
\hline & Ponto inflexão & $1253 \mathrm{~s}$ & $1236 \mathrm{~s}$ \\
\hline \multirow{5}{*}{$\begin{array}{c}\text { TM } \\
65 \\
\text { UF-Pó }\end{array}$} & Área total & 1014250 & 1665700 \\
\hline & $\begin{array}{c}\text { Área aquecimento/ } \\
\text { percentual da área } \\
\text { total }\end{array}$ & $221547 / 21,8 \%$ & $323327 / 19,4 \%$ \\
\hline & $\begin{array}{l}\text { Área resfriamento/ } \\
\text { percentual da área }\end{array}$ & $800634 / 78,9 \%$ & $1335830 / 80,2 \%$ \\
\hline & $\begin{array}{c}\text { total } \\
\text { Equação }\end{array}$ & $\begin{array}{c}\mathrm{V}=9,5 \cdot 10^{-7} \mathrm{t}^{3}-3,6 \cdot 10^{-3} \mathrm{t}^{2}+4,8 \mathrm{t}- \\
1,9 \cdot 10^{3}\end{array}$ & $\begin{array}{c}\mathrm{V}=1,2 \cdot 10^{-6} \mathrm{t}^{3}-4,4 \cdot 10^{-3} \mathrm{t}^{2}+5,7 \mathrm{t}- \\
2,2 \cdot 10^{3}\end{array}$ \\
\hline & Ponto inflexão & $1263 \mathrm{~s}$ & $1222 \mathrm{~s}$ \\
\hline \multirow{5}{*}{$\begin{array}{c}\text { MF } \\
0,8 \\
\text { UF-Pó }\end{array}$} & Área total & 1325730 & 1967580 \\
\hline & $\begin{array}{c}\text { Área aquecimento/ } \\
\text { percentual da área } \\
\text { total }\end{array}$ & $279159 / 21,1 \%$ & $401279 / 20,4 \%$ \\
\hline & $\begin{array}{l}\text { Área resfriamento/ } \\
\text { percentual da área }\end{array}$ & $1045650 / 78,9 \%$ & $1566450 / 79,6 \%$ \\
\hline & Equação & $\begin{array}{c}\mathrm{V}=1,3 \cdot 10^{-6} \mathrm{t}^{3}-4,9 \cdot 10^{-3} \mathrm{t}^{2}+6,3 \mathrm{t}- \\
2,4 \cdot 10^{3}\end{array}$ & $\begin{array}{c}\mathrm{V}=2,0 \cdot 10^{-6} \mathrm{t}^{3}-7,6 \cdot 10^{-3} \mathrm{t}^{2}+9,7 \mathrm{t}- \\
3,7 \cdot 10^{3}\end{array}$ \\
\hline & Ponto inflexão & $1256 \mathrm{~s}$ & $1266 \mathrm{~s}$ \\
\hline \multirow{5}{*}{$\begin{array}{c}\mathrm{MF} \\
1,4 \\
\text { UF-Pó }\end{array}$} & Área total & 1501550 & 2070790 \\
\hline & $\begin{array}{c}\text { Área aquecimento/ } \\
\text { percentual da área } \\
\text { total }\end{array}$ & $313103 / 20,9$ & $451733 / 21,8 \%$ \\
\hline & $\begin{array}{l}\text { Área resfriamento/ } \\
\text { percentual da área }\end{array}$ & $1186660 / 79,0 \%$ & $1615880 / 78,0 \%$ \\
\hline & Equação & $\begin{array}{c}\mathrm{V}=1,6 \cdot 10^{-6} \mathrm{t}^{3}-5,8 \cdot 10^{-3} \mathrm{t}^{2}+7,5 \mathrm{t}- \\
2,9 \cdot 10^{3}\end{array}$ & $\begin{array}{c}\mathrm{V}=1,7 \cdot 10^{-6} \mathrm{t}^{3}-6,3 \cdot 10^{-3} \mathrm{t}^{2}+8,4 \mathrm{t}- \\
3,3 \cdot 10^{3}\end{array}$ \\
\hline & Ponto inflexão & $1208 \mathrm{~s}$ & $1235 \mathrm{~s}$ \\
\hline
\end{tabular}

PT 72UF-Pó:CPS produzido a partir do soro pasteurizado a $72{ }^{\circ} \mathrm{C}$ por 15 segundos; TM 65UF-Pó: CPS produzido a partir do soro termizado a $65^{\circ} \mathrm{C}$ por 15 segundos; MF $0,8 \mathrm{UF}-\mathrm{Pó}$ : CPS produzido a partir do soro microfiltrado utilizando membrana de $0,8 \mu \mathrm{m}$ de diâmetro do poro; MF1,4UF-Pó: CPS produzido a partir do soro microfiltrado utilizando membrana de $1,4 \mu \mathrm{m}$ de diâmetro do poro. 
do produto, e apresentam grande importância para aplicação industrial.

A discreta redução dos valores de $\mathrm{V}_{\mathrm{R}} \mathrm{em}$ relação à $\mathrm{V}_{\mathrm{p}}$ pode ser devido ao estresse físico gerado pela agitação constante das soluções a uma alta temperatura na cuba do equipamento, o que teria ocasionado a perda de parte da capacidade de interação da estrutura proteica com a água. Esta perda de viscosidade pode ser atribuída também ao desdobramento das
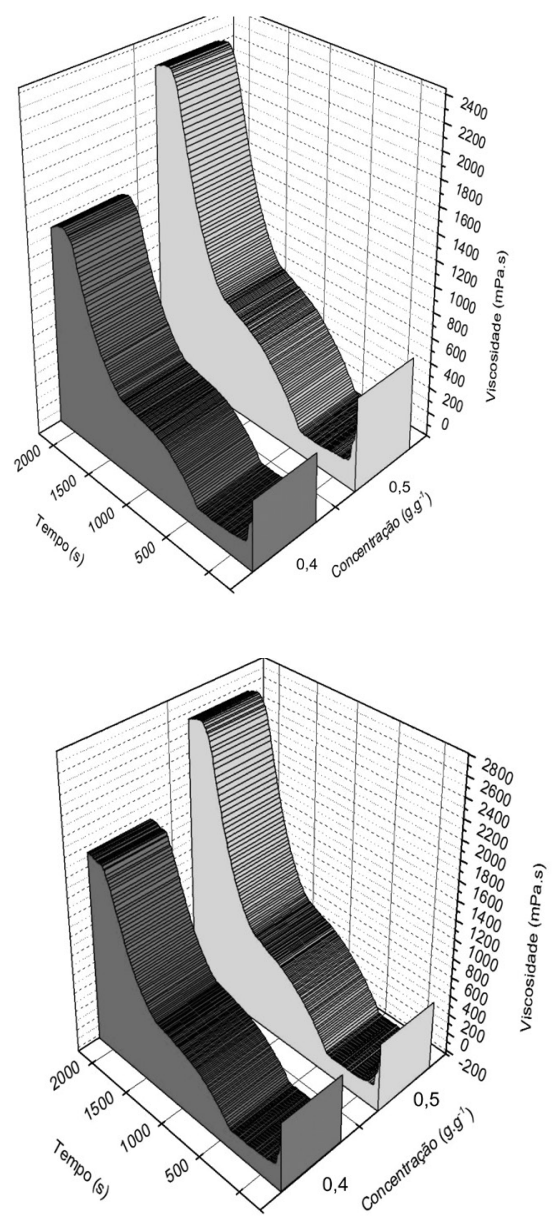

proteínas do soro, em um curto período de tempo, com a agregação de $\beta$-Lg (Oldfield et al., 1998). Essa agregação seria responsável pela redução da interação dos concentrados com a água e a diminuição da viscosidade das soluções.

Os perfis viscográficos das amostras de CPSs apresentaram um crescente aumento na viscosidade dessas soluções a partir do tempo 26 minutos (Figura 2), quando se inicia o res-
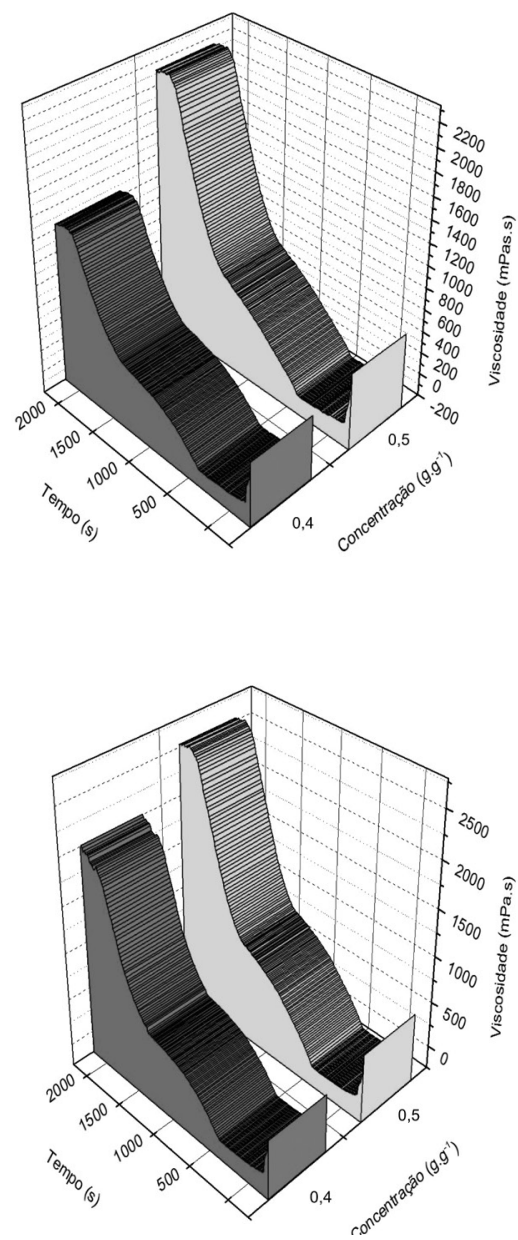

Figura 2 - Perfis viscográficos das amostras de CPSs para as duas concentrações avaliadas, (A): amostra PT 72UF-Pó, (B): amostra TM 65UF-Pó, (C): amostra MF 0,8UF-Pó, (D): amostra MF 1,4UF-Pó 
friamento para a temperatura de $30^{\circ} \mathrm{C}$, após o tempo de tratamento térmico. Os valores de $\mathrm{V}_{\mathrm{F}}$ obtidos para as amostras PT 72UF-Pó, TM 65UF-Pó, MF 0,8UF-Pó e MF 1,4UF-Pó na concentração de $0,5 \mathrm{~g} \cdot \mathrm{g}^{-1}$ foram de 2214, 2126 , 2545,7 e $2514,7 \mathrm{mPa} \cdot \mathrm{s}$, respectivamente, e portanto mais elevados que aqueles encontrados para as $V_{p}$ nesta mesma concentração. Esse aumento da viscosidade das soluções durante o resfriamento pode ser atribuído à redução da mobilidade das moléculas devido à diminuição da energia do sistema.

A variação da viscosidade para as quatro amostras avaliadas fica clara ao analisar os valores da integração dos perfis viscográficos pelo tempo de análise ( $\mathrm{g} / \mathrm{t}$ ) (Tabela 3$)$. O valor máximo de $\mathrm{J} / \mathrm{t}$ obtido no estudo foi de 843,8 $\mathrm{mPa} \cdot \mathrm{s}$ na concentração de $0,5 \mathrm{~g} \cdot \mathrm{g}^{-1}$ para a amostra MF 1,4UF-Pó, e o mínimo de 413,3 $\mathrm{mPa} \cdot \mathrm{s}$ na condição de $0,4 \mathrm{~g} \cdot \mathrm{g}^{-1}$ para a amostra TM 65UF-Pó. Apesar da integração do perfil viscográfico não mostrar informação direta em nível tecnológico, como as leituras dos pontos específicos de viscosidade $\left(\mathrm{V}_{\mathrm{p}}, \mathrm{V}_{\mathrm{R}} \mathrm{e} \mathrm{V}_{\mathrm{F}}\right)$, esta análise contribui para um resultado de alta confiança, já que coleta dados de todos os pontos de viscosidade obtidos durante o processamento, utilizando 600 números de medidas para cada amostra avaliada em determinada concentração. A importância destes dados fica evidente quando eles são comparados aos obtidos para $\mathrm{V}_{\mathrm{P}}, \mathrm{V}_{\mathrm{R}}$ e $\mathrm{V}_{\mathrm{F}}$, que são produto de apenas uma medida para cada ponto. As amostras de CPSs que mostraram maiores valores de $\mathrm{J} / \mathrm{t}$ foram também aquelas obtidas a partir dos soros tratados inicialmente pela tecnologia de microfiltração MF 0,8UF-Pó e MF1,4UF-Pó.

A mesma avaliação do efeito da concentração sobre as $V_{P}, V_{R}$ e $V_{F}$ pode ser feita para $\mathrm{J} / \mathrm{t}$, sendo a concentração de $0,5 \mathrm{~g} \cdot \mathrm{g}^{-1} \mathrm{a}$ de maior capacidade a exibir valores mais elevados de viscosidade. A similaridade entre os resultados obtidos para $\mathrm{J} / \mathrm{t}$ com os valores de $V_{p}, V_{R}$ e $V_{F}$ pode ser percebida quando são analisados os altos coeficientes de correlação entre eles (Tabela 5).

Stephani (2010) avaliou o comportamento da evolução da viscosidade de soluções de produtos lácteos proteicos em diferentes concentrações submetidos a diferentes condições de processamento térmico, utilizando o RVA como simulador de processo. O autor também obteve altos coeficientes de correlação entre a área por unidade de tempo testada com as $\mathrm{V}_{\mathrm{P}}, \mathrm{V}_{\mathrm{R}}$ e $\mathrm{V}_{\mathrm{F}}$ durante a análise dos perfis viscográficos de CPS.

\section{CONCLUSÕES}

A aplicação do tratamento térmico na matéria-prima inicial levou à obtenção de CPSs com menor capacidade de aumento na viscosidade de soluções em relação à microfiltração. Além disso, o tempo ideal de tratamento térmico para as soluções avaliadas objetivando maximizar a viscosidade durante o aquecimento foi de, em média, 10 minutos. Estes resultados possibilitam a aplicação dos CPSs de acordo com a característica desejada no produto final, ampliando a capacidade de produção de ingredientes com características

Tabela 5 - Coeficientes de correlação para área por unidade de tempo $\left(\int / \mathrm{t}\right) \operatorname{dos} C P S s$ considerando todos os tratamentos

Variável testada para correlação

Coeficiente de correlação com a área por unidade de tempo $\mathrm{J} / \mathrm{t}$

$\begin{array}{ll}\text { Viscosidade de Pico }-\mathrm{V}_{\mathrm{P}} & 0,989 \\ \text { Viscosidade de retenção }-\mathrm{V}_{\mathrm{R}} & 0,988 \\ \text { Viscosidade final }-\mathrm{V}_{\mathrm{F}} & 0,994\end{array}$


diferenciais pelas indústrias de secagem de soro. Finalmente, o RVA pode ser considerado uma ferramenta apropriada para o estudo de funcionalidades de CPSs, de modo a otimizar a determinação da aplicação tecnológica do produto pelas indústrias alimentícias.

\section{AGRADECIMENTOS}

Este trabalho foi financiado e apoiado pela Fundação de Amparo à Pesquisa do Estado de Minas Gerais (FAPEMIG) e pelo Conselho Nacional de Desenvolvimento Científico e Tecnológico $(\mathrm{CNPq})$.

\section{REFERÊNCIAS}

AMERICAN DAIRY PRODUCTS INSTITUTE (ADPI). Ingredient Description Brochure. Elmhurst, IL: ADPI, 2010.14 p.

AIMUTIS.W. R. Bioactive properties of milk proteins with particular focus on anticariogenesis. The Journal of Nutrition, v. 134, n. 4, p. 989-995, 2004.

BELOBRAJDIC, D. P.; MCINTOSH, G. H.; OWENS, J. A. Whey proteins protect more than red meat against azoxymethane induced ACF in Wistar rats. Cancer Letters, v. 198, n. 1, p. 43-51, 2003.

BENNETT, L.; POLLARD, A.; ROSS, A. S. Characterizing the properties of protein-rich ingredients and foods. In: CROSBIE, G. B.; ROSS, A. S. The RVA Handbook. New York: AACC International, 2007. p. 95-112.

BOOTH, R.; BASON, M. Principles of operation and experimental techniques. In:CROSBIE, G. B.; ROSS, A. S. The RVA Handbook. New York: AACC International, 2007. p. 1-17.

BOUnOUS, G.; MOLSON, J. H. The antioxidant system. Anticancer Research, v. 23, n. 2B, p. 1411-1416, 2003.

BRANS, G. et al. Membrane fractionation of milk: state of the art and challenges. Journal of Membrane Science, v. 243, n. 1-2, p. 263 272, 2004.

DAVIS, M. E. et al. Reducing cholesterol with hydrolyzed whey protein. Patente aplicada WO 063778, 2003.

GARCÍA, L. F.; BLANCO, S. A.; RODRÍGUEZ, F. A. R. Microfiltration applied to dairy streams: removal of bacteria. Journal of the Science of Food and Agriculture, v. 93, n. 2, p. 187-196, 2012.

INTERNATIONAL DAIRY FEDERATION (IDF). 20 B: Milk: determination of nitrogen content. Brussels, 1993. $12 \mathrm{f}$.

INTERNATIONAL DAIRY FEDERATION (IDF). 21B: Milk: determination of determination of total solids content. Brussels, 1987. 2f.

KENT, K. D.; HARPER, W. J.; BOMSER, J. A. Effect of whey protein isolate on intracellular glutathione and oxidant induced cell death in human prostate epithelial cells. Toxicology in Vitro, v. 17, n. 1, p. 27-33, 2003.

MCINTOSH, G. H.; LELEU, R. K. The influence of dietary proteins on colon cancer risk. Nutrition Research, v. 21, n. 7, p. 10531066, 2001.

METSÄMUURONEN, S.; NYSTRÖM, M. Enrichment of $\alpha$-lactalbumin from diluted whey with polymeric ultrafiltration membranes. Journal of Membrane Science, v. 337, n. 1-2, p. 248-256, 2009.

NICODEMO, A. et al. The effects of whey 
proteins on lipoprotein metabolism and oxidative stress: a review of human and animal studies. Recent Research Developments in Lipids, v. 4, n. 2, p. 245-302, 2000.

NIÑO, M. R. R. et al. Milk and soy protein films at the air-water interface. Food Hydrocolloids, v. 19, v. 3, p. 417-428, 2005.

OLDFIELD, D. J.; SINGH, H.; TAYLOR, M. W. Association of $\beta$-lactoglobulin and $\alpha$-lactalbumin with the casein micelles in skim milk heated in an ultra-high temperature plant. International Dairy Journal, v. 8, n. 9, p. 765-770, 1998.

PATINO, J. M. R. et al. Dynamic properties of soy globulin adsorbed films at the air-water interface. Journal of Colloid and Interface Science, v. 268, n. 1, p. 50-57, 2003.

PELLEGRINI, A. et al. Isolation and characterization of four bactericidal domains in the bovine beta-lactoglobulin. Biochimica et Biophysica Acta, v. 1526, n. 2, p. 131-140, 2001.

SCHUCK, P. et al. Relative humidity of outlet air: the key parameter to optimize moisture content and water activity of dairy powders. Dairy Science and Technology, v. 88, n. 1, p. 45-52, 2008.

STEPHANI, R. Comportamento de produtos lácteos proteicos em diferentes condições simuladas de processamento térmico. 2010. 149p. Dissertação (Mestrado profissional em Ciência e Tecnologia do Leite e Derivados) - Universidade Federal de Juiz de Fora, Juiz de Fora, 2010.

STEPHANI, R. et al. Behavior of dairy protein in different simulated conditions of thermal processing. In: INTERNATIONAL SYMPOSIUM ON SPRAY DRIED PRODUCTS, 5., 2012, Saint Malo-França. Proceedings... Saint Malo: INRA, 2012.p. 129.

VERMEIRSSEN, V. et al. The impact of fermentation and in vitro digestion on the formation of angiotensin-I-converting enzyme inhibitory activity from pea and whey protein. Journal of Dairy Science, v. 86, n. 2, p. 429438, 2003.

WALSTRA, P.; WOUTERS, J. T. M.; GEURTS, T. J. Dairy science and technology. New York: Taylor \& Francis Group, 2006. $768 \mathrm{p}$.

WALZEM, R. L.; DILLARD, C. J.; GERMAN, J. B. Whey components: millennia of evolution create functionalities for mammalian nutrition: what we know and what we may be overlooking. Critical Reviews in Food Science Nutrition, v. 42, n. 2, p. 353-375, 2002.

WEHR, H. M.; FRANK, J. F. Standard methods for the examination of dairy products. 17 ed. Washington: American Public Health Association, 2004. 570 p. 